\title{
CHPP OPERATION MODE OPTIMIZATION UNDER ELECTRICITY AND GAS MARKET CONDITIONS USING A GENETIC ALGORITHM
}

\author{
J. Kozadajevs ${ }^{1}$, A. Dolgicers ${ }^{1}$, D. Boreiko ${ }^{1}$ \\ ${ }^{1}$ Riga Technical University, Institute of Power Engineering, \\ 12-1, Azenes Str., Riga, LV-1010, LATVIA \\ E-mail: jevgenijs.kozadajevs@rtu.lv
}

The article presents an operation planning optimisation approach using a genetic algorithm for CHPPs in an urban heat supply zone. Changes in market environment will result in a significant change in energy system planning and operation. For efficient production planning in the liberalized power markets, it is paramount to determine the optimal strategies over a time horizon. Solution of an optimization task of such complexity requires a well-crafted set of tailored modelling, simulation, optimization, and forecasting tools. A well-designed solution is unthinkable without a great number of production units, such as gas turbines, steam turbines, heat-only boilers, and thermal storages, reflected by the optimization model.

Keywords: CHPP operation, electricity market, gas market, genetic algorithm, optimization.

\section{INTRODUCTION}

Combined heat and power plants (CHPPs) simultaneously generate electricity and heat on the basis of cogeneration. CHPPs are widespread in the Nordic countries, where domestic heat consumption is high, especially in winter, and district heating as a thermal load for CHPPs is typical of cities and towns [1]. Historically, CHPPs are built in places with heat demand, and the combined operating mode is the main one for CHPPs during the heating season when operation takes place according to the heat schedule, i.e., the production of electricity depends on the production of heat, the latter being a priority.

However, nowadays CHPP operation becomes more complicated when power market conditions change the game. Liberalization of the power markets - development of the electricity market, primary 
energy source markets and potential development of the heat energy market - becomes an integral part of energy policy planning.

New markets will result in a significant change in energy system planning and operation. Production planning in the liberalized power markets is to determine the optimal strategies over a time horizon (a day, a week, a month or a year) so that the overall net profit can be maximised subject to production constraints. CHPP operation planning optimization for a time horizon is a very complicated task. The interdependence between heat and power generation imposes a great challenge in operation optimization. It must be done in coordination between heat and power, taking into account the non-uniform equipment fleet [2].

Moreover, the liberalized power and gas market introduces more uncertainties than before, operation optimization should cover not only the operation of a single CHP plant, but the operation of all CHPPs in a heat supply zone (Fig. 1). This means that a great number of production units, such as gas turbines, steam turbines, heat-only boilers, and thermal storages should be added to the optimization model.

The solution of an optimization task of such complexity requires a well-crafted set of tailored modelling, simulation, optimization, and forecasting tools.

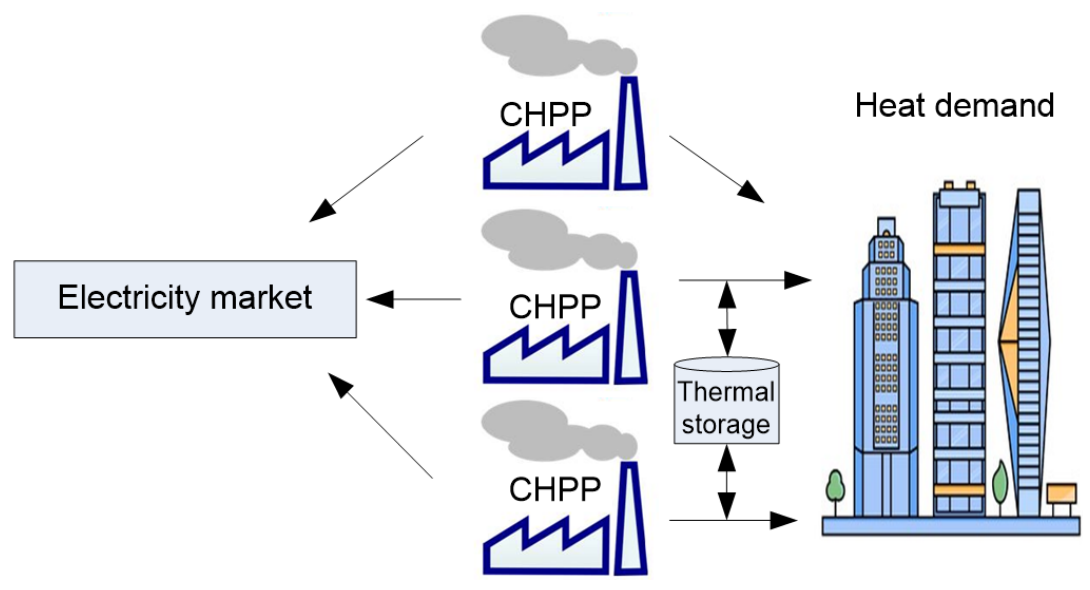

Fig. 1. The supply of CHPPs.

The great challenge for operation planning optimization is the choice of the optimization method. First of all, a CHPP optimization problem is not linear, it has a large number of decision variables, and note should be taken of the exponential growth of the array of variables when the planning time span increases. The timed nature of operation and the limitations imposed by launch and stop operations add more complexity to the task (for example, gradienttype mathematical solvers are unfit for such a type of task).
A lot of work has been done during the recent years to improve CHPP operation optimization [3]-[11]. The major focus in most papers is on discovering what type of models and optimization algorithms to use to render effective solutions for CHPP operation planning optimization for a time period, and the longer the period, the better.

Over the recent years, the Genetic Algorithm (GA) has become one of the most popular mathematical solvers for such a type of problems [3]-[11]. A genetic algorithm is a type of numerical algorithms, 
suitable for nonlinear tasks, including interrupted function tasks. However, GA is not the best performer when it needs to deal with larger sets of decision variables.

Upon summarising the results of the publications devoted to CHPP operation planning optimization, we can conclude that the non-uniform CHPP operation planning optimization task for a heating zone under power market conditions (an electricity market and a developing gas market) has not yet been considered widely enough for the time being.

The overall objective of our study is to develop an operation planning optimization model for the CHPPs of the city of Riga, using a genetic algorithm for operation planning optimization, electricity market and gas market models for power market simulation, Riga CHPP 1, Riga CHPP 2.1 and Riga CHPP 2.1 models for the simulation of heat and power production. The objective function for the optimization task is to maximise the net profit for the operation of the CHPPs.

Riga CHPPs and production units are described in the next section of this paper. It should be noted that several reconstruction projects have been implemented at Riga CHPPs to improve their operation flexibility under market conditions: recon- struction of the heat-only boilers to meet the maximum heat load during the coldest days and to meet the heat load during CHPP maintenance; thermal storage installation to shift the heat load chart away from electricity production. In this paper, the operation planning optimization time period is 24 hours.

For future work, it is planned to increase the planning period and to use forecasting for power market prices and heat loads.

The main contributions of this paper are summarised as follows:

- A genetic algorithm is successfully applied for planning the operation of the CHPPs of the city of Riga for a time period of 24 hours with an objective to maximise their net profit;

- The effectiveness of the proposed approach is analysed on the basis of the operation planning optimization results.

The rest of the article is organised as follows: Section 2 is devoted to the description of the production units of Riga CHPPs, the description of the Nord Pool power market model and the description of the model of the developing gas market. Section 3 contains a description of the optimization model based on the genetic algorithm. Section 4 contains optimization results and result analysis.

\section{METHODOLOGY AND MODELS}

\section{A. Riga CHPPs}

Riga CHPP No. 1, Riga CHPP No. 2.1 and Riga CHPP No. 2.2 meet $69 \%$ of the heat needs of the city of Riga.

The production units of CHPP No. 1 are as follows: a gas-steam combined cycle (CCGT) twin unit with an installed thermal power capacity of $145 \mathrm{MW}_{\text {th }}$ and an installed electrical power capacity of
$144 \mathrm{MW}_{\mathrm{el}}$, also heat-only boilers (HOBs) with an installed capacity of $348 \mathrm{MW}_{\text {th }}$. The total thermal power capacity of CHPP No. 1 is $493 \mathrm{MW}_{\text {th }}$. Natural gas is used as the primary energy source. In case of a gas supply outage, diesel fuel could be used as a backup fuel for the heat-only boilers. 
Table 1. Riga CHPP No. 1

\begin{tabular}{|l|c|c|c|c|}
\hline Riga CHPP 1 & No. & Pe, MW & Pq, $\mathbf{M W}_{\text {th }}$ & Pq total \\
\hline Cogeneration & 1 & 144 & 145 & 145 \\
\hline Heat-only boilers & 3 & - & 116 & 348 \\
\hline Total & - & 144 & - & 493 \\
\hline
\end{tabular}

CHPP No. 1 operation modes:

1. Cogeneration:

1.1. 2 GTs + ST (Pq - heat load; Pq > $45 \mathrm{MW}$ up to $\mathrm{Pq}<145 \mathrm{MW})$;

1.2. $1 \mathrm{GT}+\mathrm{ST}(\mathrm{Pq}>45$ up to $66 \mathrm{MW})$.

2. Cogeneration with heat-only boilers:

2.1. 2 GTs + ST + HOB $(\mathrm{Pq}>145 \mathrm{MW}$, up to a total of $493 \mathrm{MW}_{\mathrm{th}}$ );

CHPP 2.1 power unit's total electrical power in cogeneration mode is $413 \mathrm{MW}_{\mathrm{el}}$ and $442 \mathrm{MW}_{\text {el }}$ in condensing mode, respectively, and the total thermal power in cogeneration mode is $274 \mathrm{MW}_{\text {th }}$. CHPP 2.2 power unit's total electrical power in cogeneration
2.2. $1 \mathrm{GT}+\mathrm{ST}$ and $\mathrm{HOB}(\mathrm{Pq}>66 \mathrm{MW}$, up to a total of $414 \mathrm{MW}_{\text {th }}$ ).

3. $\mathrm{HOB}-12 \mathrm{MW}_{\text {th }}$ up to $348 \mathrm{MW}_{\text {th }}$, where GT is a gas turbine and ST is the steam turbine, and HOB is the heat-only boiler.

mode is $419 \mathrm{MW}_{\mathrm{el}}$ and $439 \mathrm{MW}_{\mathrm{el}}$ in condensing mode, respectively, and the total thermal power in cogeneration mode is $270 \mathrm{MW}_{\text {th }}$. Heat-only boilers - No. 1, 2, 3, 4,5 with a total thermal power of $580 \mathrm{MW}_{\text {th. }}$.

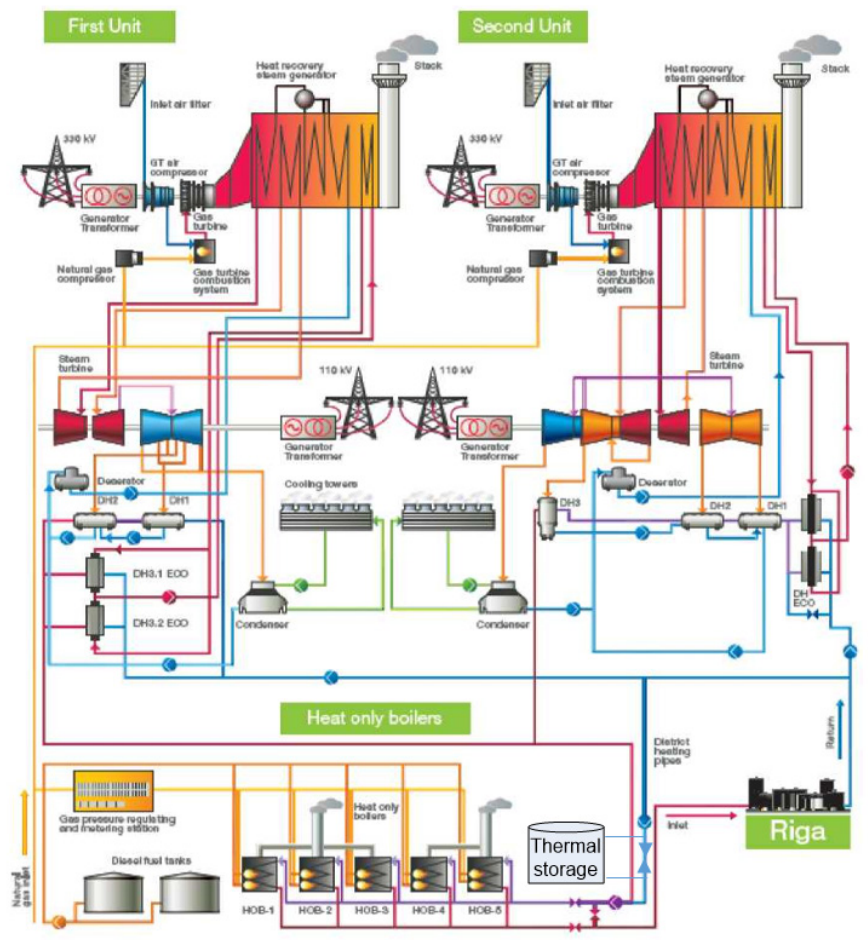

Fig. 2. Illustration of Riga CHPP 2.1 and CHPP 2.2. 
In case of a gas supply outage, diesel fuel could be used as a backup fuel for the heat-only boilers. In the year 2020, a thermal storage was installed for CHPP 2.1 and
CHPP 2.2 with a total capacity of $550 \mathrm{MWh}$ and a charge/discharge capacity of $150 \mathrm{MW}$ per hour.

Table 2. Riga CHPP 2

\begin{tabular}{|l|c|c|c|c|}
\hline Riga CHPP 2 & No. & Pe, MW & Pq, MWth & Pq total \\
\hline Cogeneration unit CHPP 2.1 & 1 & 413 & 274 & 274 \\
\hline Condensing unit CHPP 2.1 & 1 & 442 & 0 & 0 \\
\hline Cogeneration unit CHPP 2.2 & 1 & 419 & 270 & 270 \\
\hline Condensing unit CHPP 2.2 & 1 & 439 & 0 & 0 \\
\hline Heat-only boilers & 5 & - & 116 & 580 \\
\hline Total cogeneration at CHPP 2 & - & 832 & - & 1124 \\
\hline Total condensing at CHPP 2 & - & 871 & - & - \\
\hline
\end{tabular}

The equipment set of CHPP 2.1 and CHPP 2.2 allows for several main operation modes.

\section{Cogeneration mode:}

1.1. CHPP 2.1 (Pq from $180 \mathrm{MW}_{\text {th }}$ up to $274 \mathrm{MW}_{\text {th }}$ and electrical power from $190 \mathrm{MW}_{\text {el }}$ up to $413 \mathrm{MW}_{\mathrm{el}}$ );

1.2. CHPP 2.2 (Pq from $160 \mathrm{MW}_{\text {th }}$ up to $270 \mathrm{MW}_{\text {th }}$ with electrical capacity from $185 \mathrm{MWel}$ up to $419 \mathrm{MW}_{\mathrm{el}}$ );

1.3. CHPP 2.2 Opflex mode $(\mathrm{Pq}$ from $145 \mathrm{MW}_{\text {th }}$ up to $160 \mathrm{MW}_{\text {th }}$ and electrical power from $148 \mathrm{MW}_{\mathrm{el}}$ up to $175 \mathrm{MW}_{\mathrm{el}}$ );

1.4 CHPP 2.1 and CHPP 2.2.

2. Condensing mode:

2.1. CHPP 2.1 electrical power from $190 \mathrm{MW}_{\mathrm{el}}$ up to $442 \mathrm{MW}_{\mathrm{el}}$;

2.2. CHPP 2.2 electrical power from $180 \mathrm{MW}_{\text {el }}$ up to $439 \mathrm{MW}_{\text {el}}$;

2.3. CHPP 2.1 and CHPP 2.2.
3. Mixed operation mode:

3.1. CHPP 2.1 power unit: Pq from $60 \mathrm{MW}_{\text {th }}$ up to $<180 \mathrm{MW}_{\text {th }}$ and electrical power from $190 \mathrm{MW}_{\mathrm{el}}$ up to $413 \mathrm{MW}_{\mathrm{el}}$;

3.2. CHPP 2.2 power unit: Pq from $20 \mathrm{MW}_{\text {th }}$ up to $<160 \mathrm{MW}_{\text {th }}$ and electrical capacity from $180 \mathrm{MW}_{\mathrm{el}}$ up to $419 \mathrm{MW}_{\mathrm{el}}$.

4. CHPP power unit and heat-only boilers.

5. CHPP power unit and heat-only boiler with thermal power from $12 \mathrm{MW}_{\text {th }}$ up to $580 \mathrm{MW}_{\text {th}}$,

where electrical power $-P$ is a function of thermal power $-Q$, and is represented with a 2nd degree polynomial (1). CHPP fuel/ natural gas consumption $F$ is a function of electrical power (2). For every CHPP and every production unit and mode, functions $P=f(Q)$ and $F=f(P)$ are different.

$$
\begin{aligned}
& P=a * Q^{2}+b * Q+C \\
& F=q * P^{2}+w * P+r
\end{aligned}
$$




\section{B. The Nord Pool Market}

Nord Pool runs the leading power market in Europe and offers day-ahead and intraday markets to spot customers. The day-ahead market is the main arena for power trading, and the intraday market supplements the day-ahead market and helps secure balance between supply and demand.

The Nordic and Baltic areas are divided into bidding areas by the relevant transmission system operator in order to handle congestions in the electricity grid. Bidding areas can have a balance, deficit or surplus of electricity. Electricity will flow from areas where the price offered is lower towards areas where the demand is high and the price offered is higher.

If the transmission capacity between bidding areas is not sufficient to reach full price convergence across the areas, congestions will lead to bidding areas having different prices.

If the flow of power between bidding areas is within the capacity limits set by the transmission system operators, the area prices in these different bidding areas will be identical.

All the producers are paid according to the calculated area price, and similarly all the consumers pay the same price [12].

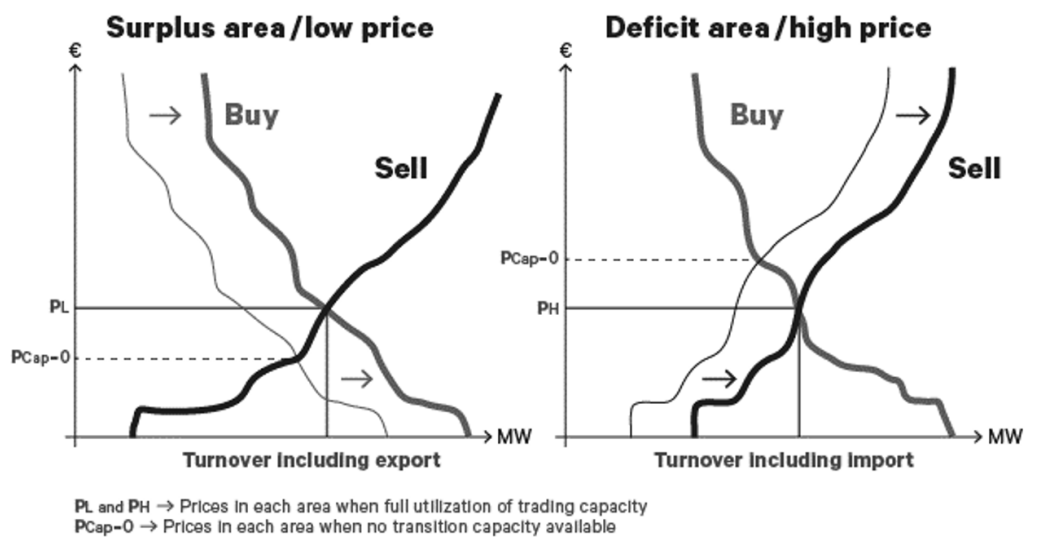

Fig. 3. Electricity pricing.

For our task in this article, the Nord Pool market model is represented by Lat-

\section{Gas Market}

The European Union began a liberalization process during the last decade in order to create an internal market for gas by breaking up vertically integrated national companies, allowing for entry on the supply side and consumer-switching on the demand side. The opportunity to purchase gas from different suppliers does not eliminate possible constraints in vian area electricity prices for 24 hours, with a time step of one hour.

gas delivery (gas transmission capacity limits), gas storage (storage capacity limits, storage charge/discharge limits) and so on. In this case, the gas market model for our optimization task is represented by several gas suppliers, each of them offering a specific volume at a specific price [17]. 


\section{A. Methodology}

The objective function for the optimization task is to maximise the net profit for the operation of Riga CHPP 1, CHPP 2.1, and
CHPP2.2, the thermal storage and the heatonly boilers for a time period of 24 hours.

$$
\begin{gathered}
F=\sum_{i=1}^{24} C_{P_{-} i}\left(P_{C H P P 1 i}+P_{C H P P 2.1 i}+P_{C H P P 2.1 i}\right)- \\
-\sum_{i=1}^{24}\left(V_{g C H P P 1 i}+V_{g C H P P 2.1 i}+V_{g C H P P 2.1 i}+V_{g H B}\right) C_{g}- \\
- \text { penalty }{ }_{C H P P 1+C H P P 2.1+C H P P 2.2} \rightarrow \max
\end{gathered}
$$

where

$C_{p_{-} i}-$ an hourly electricity price from Nord Pool spot exchange, $€ / \mathrm{MWh}$; the penalty is every CHPP unit's start/stop cost, $€$.

$P_{C H P P 1 i}, P_{C H P P 21 i}, P_{C H P P 21 i}$ represent the electricity sold/output by CHPP 1, CHPP 2.1, CHPP 2.2 every hour, MWh during hour $i$; further sold/output electricity is a function of produced electricity:

$$
\begin{aligned}
& P_{C H P P 1 i}=f\left(P_{C H P P 1 p i}\right) \\
& P_{C H P P 2.1 i}=f\left(P_{C H P P 2.1 p i}\right) \\
& P_{C H P P 2.1 i}=f\left(P_{C H P P 2.1 p i}\right)
\end{aligned}
$$

where

$P_{C H P P 1 p i}, P_{C H P P 2.1 p i}, P_{C H P P 2.1 p i}-$ the electricity produced by CHPP 1, CHPP 2.1, CHPP 2.2, MWh, during hour $i$.

Further electricity produced by every CHPP is a function of produced heat energy, MWh, during hour $i$ :

$$
\begin{aligned}
& P_{C H P P 1 p i}=f\left(Q_{C H H P 1 p i}\right) \\
& P_{C H P P 2.1 p i}=f\left(Q_{C H H P 2.1 p i}\right) \\
& P_{C H P P 2.2 p i}=f\left(Q_{C H H P 2.2 p i}\right)
\end{aligned}
$$

where

$f\left(Q_{\text {CHHPpi }}\right)$ is the heat energy produced by the CHPP without heat-only boilers; $f\left(Q_{C H H P p i}\right)$ is represented in Eq. (1); $Q_{C H H P \text { i }}$ is the heat energy produced by every CHPP for every hour, in total 72 variables are decision variables for the optimization problem.

Further, the total natural gas consumption of CHPPs is represented as a function of the heat energy produced. It should be mentioned that the condensing operation mode is also taken into account.

$$
\begin{aligned}
& V_{g C H P P 1 i}=f\left(Q_{C H H P 1 p i}\right) \\
& V_{g C H P P 2.1 i}=f\left(Q_{C H H P 2.1 p i}\right) \\
& V_{g C H P P 2.1 i}=f\left(Q_{C H H P 2.2 p i}\right)
\end{aligned}
$$

where

$V_{\text {gCHPPi }}$ is the gas consumption in MW for electricity and heat production;

further $C_{g}$ is the natural gas price as a function of natural gas volume. This function is described in the gas market section:

$C_{g}=f\left(\sum_{i=1}^{24}\left(V_{g C H P P 1 i}+V_{g C H P P 2.1 i}+V_{g C H P P 2.1 i}+V_{g H B i}\right)\right.$

where

$V_{g H B}$ is the gas consumption $(\mathrm{MWh})$ for heat production by the heat-only boilers every hour. 
Constraints:

$Q_{C H P P 1 p_{\_} \min } \leq Q_{C H P P 1 p i} \leq Q_{C H P P 1 p_{-} \max }$

$Q_{C H P P 2.1 p \_\min } \leq Q_{C H P P 2.1 p i} \leq Q_{C H P P 2.1 p \_\max }$

$Q_{C H P P 2.2 p \_\min } \leq Q_{C H P P 2.2 p i} \leq Q_{C H P P 2.2 p \_\max }$

where

$Q_{C H P P P_{\text {_min }}}$ and $Q_{\text {CHPPP_max }}$ are technical (design) constraints for heat production for every CHPP (without the heat-only boilers).

$P_{\text {CHPP1p_min }} \leq P_{\text {CHPP1pi }} \leq P_{\text {CHPP1p_max }}$

$P_{\text {CHPP2.1p_min }} \leq P_{C H P P 2.1 p i} \leq P_{C H P P 2.1 p_{-} \max }$

$P_{\text {CHPP2.2p_min }} \leq P_{C H P P 2.2 p i} \leq P_{C H P P 2.2 p \_m a x}$

where

$P_{\text {CHPP } \_ \text {min }}$ and $P_{\text {CHPPp_max }}$ are technical constraints for electrical energy production for every CHPP.

$Q_{H B \min } \leq Q_{H B} \leq Q_{H B \max }$

where

$Q_{H B \min }$ and $Q_{H B \max }$ are technical constraints for heat production by the heat-only boilers.

$0 \leq Q_{\text {storageuse_i }} \leq Q_{\text {storageuse_max }}$

where

$Q_{\text {storageuse_i }}$ is the use of heat from the heat energy storage in every hour.

$0 \leq Q_{\text {storage } \__{-}} \leq Q_{\text {storage }_{-} \max }$

where

$Q_{\text {storage } i}$ is the heat stored in the heat energy storage for every hour.

$Q_{C H P P 1 p_{i}}+Q_{C H P P 2.1 p_{i}}+Q_{C H P P 2.2 p i}+Q_{\text {storageuse }}+Q_{H B} \geq Q_{d}$

where

$Q_{d}$ is a function of outdoor temperature $Q_{d}=f(T)$ and represents the heat demand. The production amount of all the units must meet the heat demand. 
As shown in this section, CHPP optimization problem is a nonlinear one, with a large number of decision variables. The timed character of operation and the limitations imposed by the launch and stop opera-

\section{B. Genetic Algorithm}

The genetic algorithm has been inspired by the process of natural selection where the fittest individuals are selected for reproduction in order to produce offspring in the next generation. The process of natural selection starts with the selection of the fittest individuals from a population. They produce offspring that inherit the characteristics of the parents and will be added to the next generation. If parents have better fitness, their offspring will be better than their parents and have a better chance at surviving. This process keeps on iterating and at the end, the population will consist of the fittest individuals or, in other words, the best values of decision variables will be found [13].

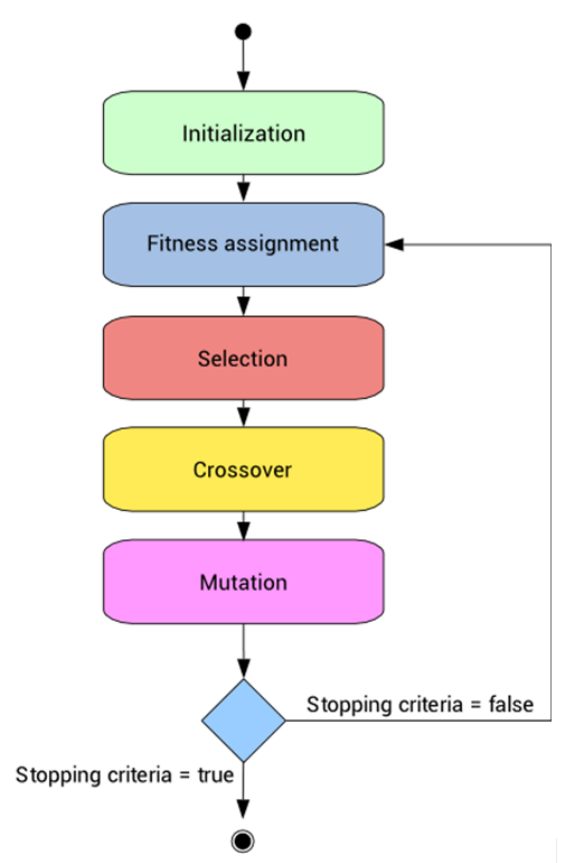

Fig. 4. The structure of a genetic algorithm. tions add more complexity to the task. All of the above makes the choice of a genetic algorithm for the optimization problem the most preferable option.

The present paper does not focus on the details and arrangement of genetic algorithms. However, some important aspects of GA application in our task should be mentioned. These aspects will be discussed in the next section. Optimization algorithms - and the genetic algorithm is not an exception - sometimes converge towards a local minimum, a point where the function value is smaller than at nearby points but not the smallest one in the whole search space. The genetic algorithm can sometimes overcome this deficiency with the right settings.

Now let us discuss genetic algorithms in general. Five main phases are considered in a genetic algorithm: Initial Population, Fitness Function, Selection, Crossover and Mutation.

The optimization process begins with a set of individuals called a Population. Each individual is a solution to the problem we want to solve. The closer the initial population values to the optimum, the better.

The idea of the Selection phase is to select the fittest individuals and let them pass their genes on to the next generation. Two pairs of individuals (parents) are selected based on their fitness scores. Individuals with a high fitness are selected for reproduction.

Crossover is the most significant phase in a genetic algorithm. For each pair of parents to be mated, a crossover point is chosen at random from within the genes.

In Mutation, some of the genes can be subjected to a mutation with a random probability [15]. 


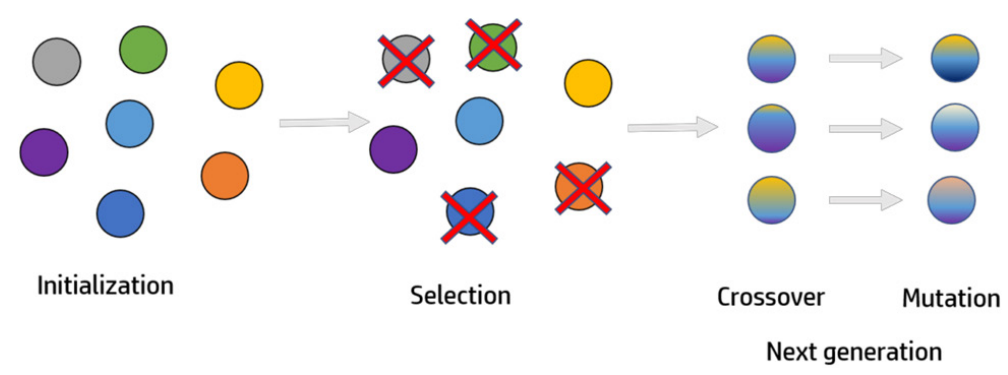

Fig. 5. Genetic algorithm.

\section{Genetic Algorithm Implementation}

One of the factors of our problem is the redundancy of each of the CHPP units. What is more, each CHPP unit can be turned off for the entire planning period. This type of operation introduces certain difficulties for the use of the genetic algorithm. This is a type of the so-called local minimum problem. To overcome this deficiency, the choice of the initial population for the genetic algorithm is very important. A special subprogram is developed for the genetic algorithm input (Fig. 6). The idea of this subprogram is to choose the best combination of the three CHPP units (the startup set) for GA input. The criterion for the best combination is the objective function Eq. (3) - and fulfilment of constraints. However, only three operation modes are possible for the initial population: (1) the power plant unit is off, (2) minimum power and (3) maximum power for every hour of the planning period. This means that we do not conduct any optimization, just enumeration with the choice of the best decision.

The next important step is the choice of the decision variable range. It is more practical to reserve the whole range from 0 up to $Q_{C H P P \text { max }}$ but if the value is less than $Q_{C H P P \text { min }}$, it means that the CHPP unit is off. The turning on/off of the CHPP units is represented in the objective function with a penalty, Eq. (3).

The next operation is the choice of the number of individuals for the elite, cross- over and mutation. Practice shows that the number for the elite should be quite high for tasks with a great number of decision variables, up to $25 \%$ from the population. The mutation can be conducted after the crossover; however, the mutation should be with strong random and the number of individuals for the mutation should not exceed $20 \%$ of all the individuals. Mutation can make individuals unfit/unsuitable for constraints; on the other hand, strong mutation is vital to overcome local minima.

The gas costs are calculated based on the total gas consumption and the available gas supply volumes and the gas prices on the market. The $\mathrm{CO}_{2}$ emission costs are added to the calculated gas costs.

It should be mentioned that for operation planning optimization the initial state of every CHPP unit and heat storage must be defined. This approach makes it possible to use optimization in a rolling way, i.e., the end of a planning period is the start of the next planning period. This way of optimization for a longer period has its disadvantages; however, heat demand forecasting and electricity price forecasting are not accurate either for a time period longer than 24 hours, and all kinds of such planning can be used only for informational purposes.

The proposed optimization approach is implemented in MATLAB, using the custom genetic algorithm.

To reduce the number of decision vari- 
ables, the method of decomposition, in other words, division of the problem into two separate optimization layers, is used. At the top layer, the population forms a heat production task for each CHPP unit (described in detail above). At the bottom layer, this task is distributed among the CHPP assemblies with a check for the possibility of such a mode, including inheritance from the previous hour mode.

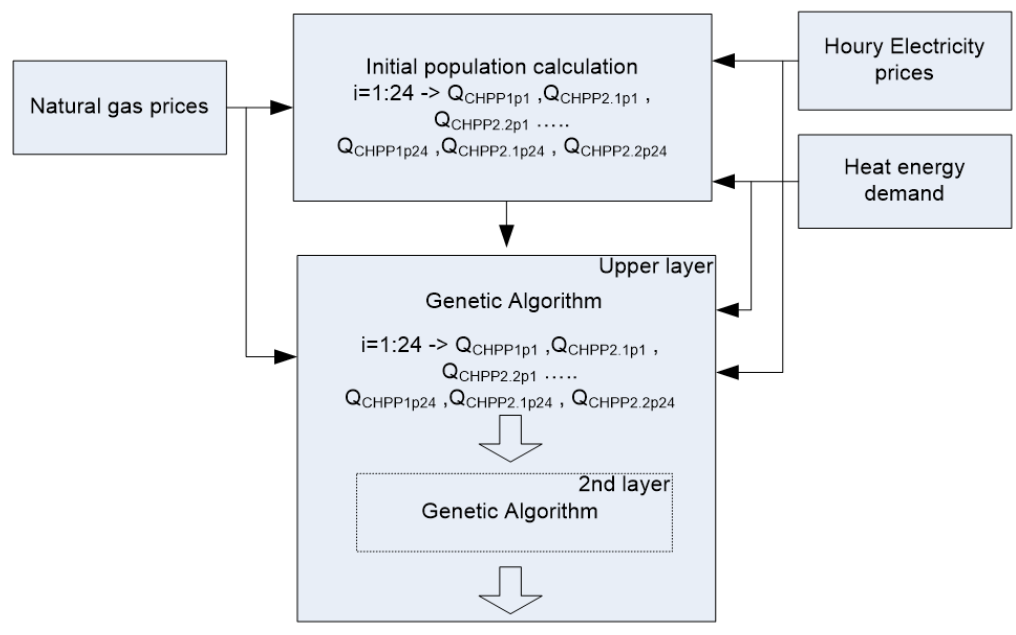

Fig. 6. The method of decomposition.

\section{RESULTS}

In this section we present optimization results for different days with different heat demand and with gas price and electricity price fluctuation. The heat demand and the electricity prices are taken from a historical database. Figures 7 and 8 present an easy scenario of a cold winter day with a high heat demand and a very low gas price of $5 € / \mathrm{MWh}$ (plus $6.67 € / \mathrm{MWh}$ as $\mathrm{CO}_{2}$ emission expenses). It should be mentioned that HOB (Figs.7-10) represents total thermal power production by CHPP1 and CHPP2 HOBs. For a starting point, all units are in cogeneration mode. The value of the objective function is $96019 €$. The profit is so low because we are not taking into account the income from the heat sold. The value of the heat sold is equal to the heat demand, and the heat price is constant, so it can be excluded from the objective function. If we change the gas price from $5 €$ up to $20 €$ (one supplier with a fixed price), all the CHPP units will be disconnected (Fig. 9). For this scenario, the heat-only boilers can meet the whole heat demand. The value of the objective function is $-562161 €$ (a negative value).

Here we can see a strong interdependence between the price of gas (and emissions) and the electricity price for optimal operation planning.

Now let us consider a natural gas price of $18 € / \mathrm{MWh}$. The operation planning results are shown in Figs. 10 and 11. One can see that CHPP 1 is not active for the whole operation planning period. CHPP 1 has a low maximum electrical power output and high maximum heat power. This 
CHPP was designed to meet the whole heat demand when the heating season was over. When the electricity price is high and the heat demand is not sufficient for the operation of all the CHPP units, the operation of CHPP 2.1 and CHPP 2.2 is a priority because they can produce more electricity with the same heat production. This situation is shown in Figs. 10 and 11. (CHPP1 Start/Stop expenses makes more feasible to run $\mathrm{HOB}$ to cover the remaining heat load).

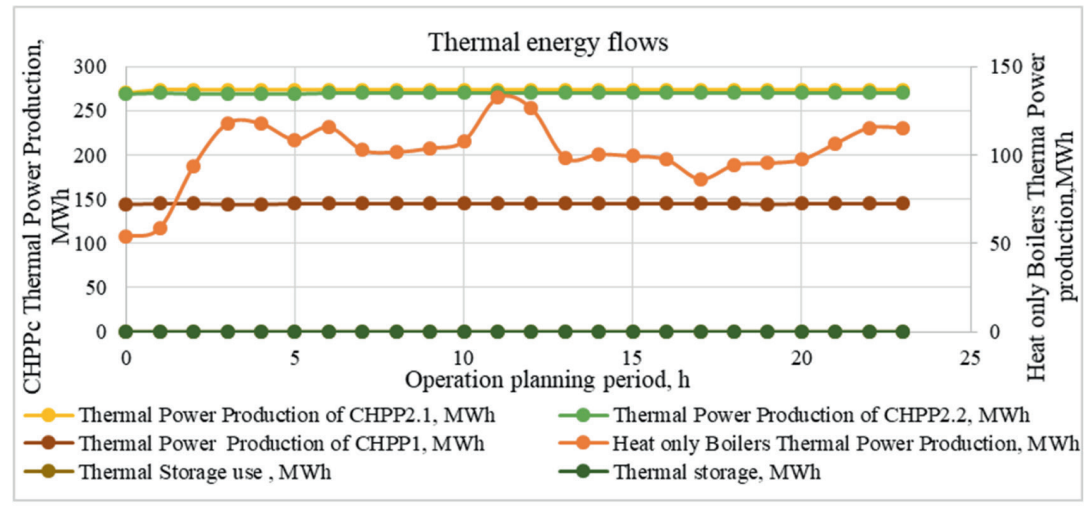

Fig. 7. Heat energy flows; the natural gas price is $5 € / M W h$.

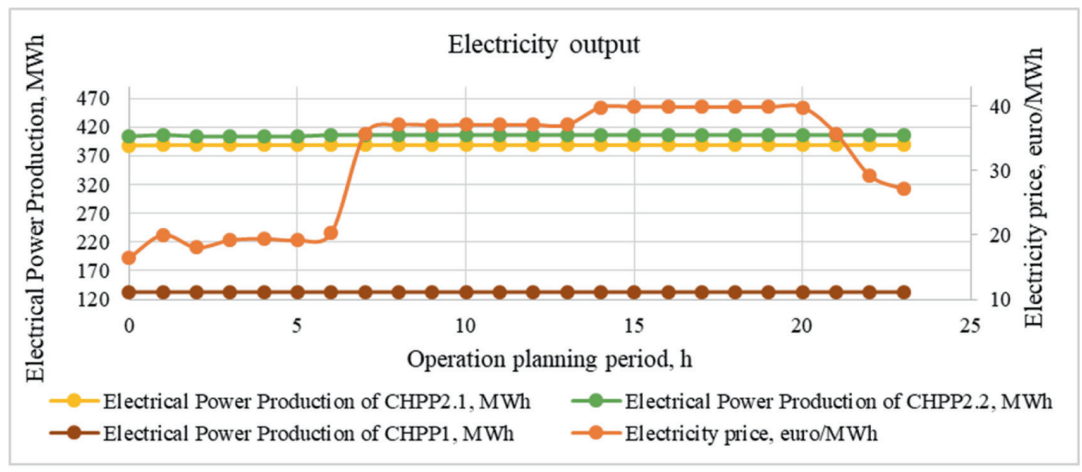

Fig. 8. Electricity output; the natural gas price is $5 € / \mathrm{MWh}$.

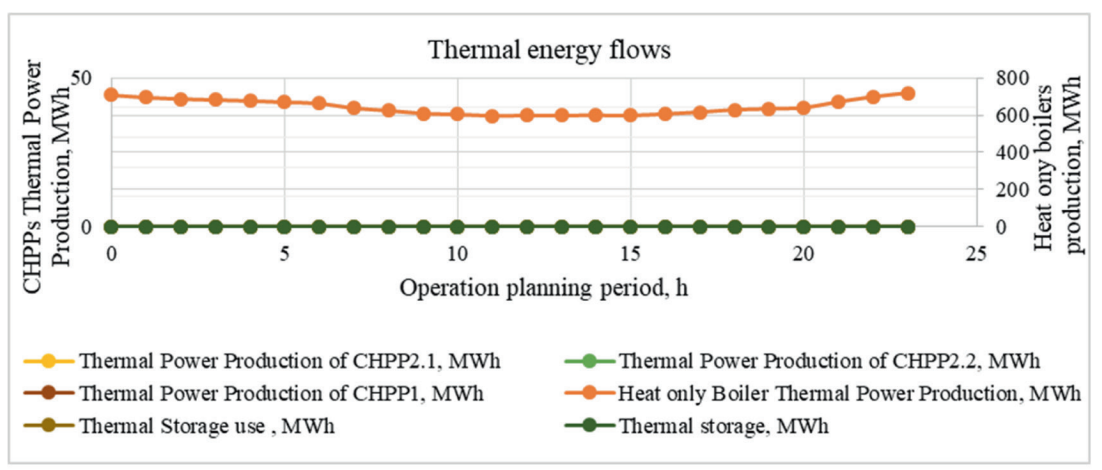

Fig. 9. Heat energy flows. Heat only boilers (from CHPP1 and CHPP2) are in operation; the natural gas price is $20 € / \mathrm{MWh}$. 


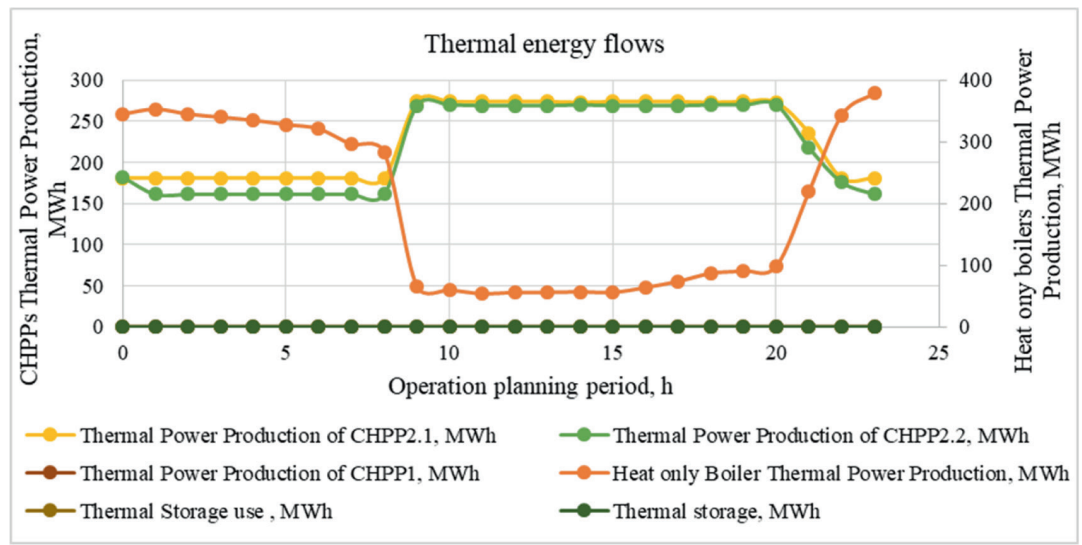

Fig. 10. Heat energy flows at a natural gas price of $18 € / \mathrm{MWh}$.

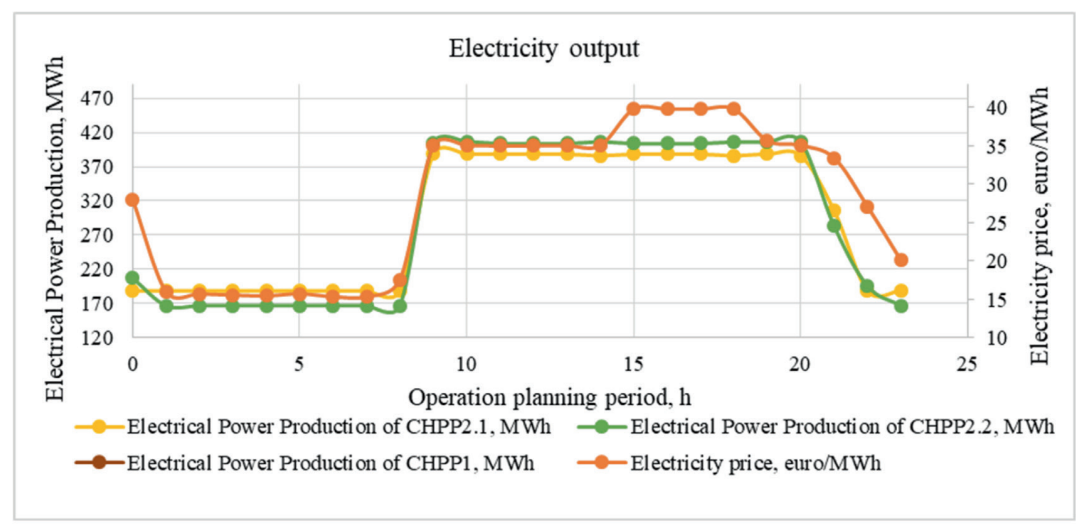

Fig. 11. Electricity output at a natural gas price of $18 € / \mathrm{MWh}$.

\section{CONCLUSIONS}

The application of the proposed GAbased optimization technique to the set of possible states of a hybrid system allows selecting a subset of states that:

a. provides the greatest possible profit;

b. guarantees the feasibility of the operation mode and provides consumers with the necessary heat throughout the entire planning interval;

c. does not create unacceptable operating modes for the equipment.

Decomposition of the problem into two mutually related layers makes it possible to create an optimal objective function for the implementation of the available computational resources, reduce the number of decision variables and significantly speed up the process of finding the optimum. Part of the calculations at the lower layer can be performed only once and then they have to be replaced by interpolation of the calculated table. The application of the proposed method in a sliding window manner allows solving the optimization problem for any planning period. 
The research has been funded by the Ministry of Economics of the Republic of Latvia, project "Trends, Challenges and Solutions of Latvian Gas Infrastructure Development (LAGAS)" (No. VPP-EMINFRA-2018/1-0003); project "Innovative Smart Grid Technologies and Their
Optimization (INGRIDO)" (No. VPP-EMINFRA-2018/1-0006).

The research has also been supported by the Latvian Council of Science, project "Management and Operation of an Intelligent Power System (I-POWER)" (No. lzp2018/1-0066).

\section{REFERENCES}

1. Environmental and Energy Study institute. (n.d.). Combined Heat and Power (CHP). Available at https://www.eesi.org

2. Rong, A., \& Lahdelma, R. (2011). Optimal Operation of Combined Heat and Power Based Power Systems in Liberalized Power Markets. Encyclopedia of Life Support Systems (EOLSS). Oxford: Eolss Publishers. Available at https://www.eolss. net/sample-chapters/C05/E6-39-14-00.pdf

3. Ivanova, P., Linkevičs, O., \& Sauhats, A. (2017). Cost-benefit analysis of CHP plants taking into account air cooling technologies. In 2017 IEEE International Conference on Environment and Electrical Engineering and 2017 IEEE Industrial and Commercial Power Systems Europe, (pp. 55-60), 6-9 June 2017, Milan, Italy. doi:10.1109/ EEEIC.2017.7977404

4. Petrova, T., Varfolomejeva, R., Sauhats, A., \& Linkevičs, O. CHPP operational mode planning at electricity market conditions. In Advances in Information, Electronic and Electrical Engineering (AIEEE 2015): Proceedings of the 2015 IEEE 3rd Workshop, (pp. 59-64), 13-14 November 2015, Riga, Latvia. doi:10.1109/AIEEE.2015.7367290

5. Dolgicers, S., Guseva, A., Sauhats, O., Linkevics, O., Mahnitko, A., \& Zicmane, I. (2009). Market and environmental dispatch of combined cycle CHP plant. In IEEE Bucharest Power Tech Conference, (pp. 1-4), 28 June-2 July 2009, Bucharest, Romania.
6. Linkevics, O., \& Sauhats, A. (2005). Formulation of the objective function for economic dispatch optimisation of steam cycle CHP plants. In Power Tech, IEEE, (pp. 1-6), 27-30 June 2005, St. Petersburg, Russia.

7. Sahoo, P.K. (2008). Exergoeconomic Analysis and Optimization of a Cogeneration System Using Evolutionary Programming. Applied Thermal Engineering, 28 (13), 1580-1588.

8. Ahmadi, P., Barzegar, A.H., Ghaffarizadeh, A., \& Saidi, M.H. (2011). ThermoEconomic-Environmental Multi-Objective Optimization of a Gas Turbine Power Plant with Preheater Using Evolutionary Algorithm. International Journal of Energy Research, 35 (5), 389-403. doi:10.1002/ er.1696.

9. Roosen, P., Uhlenbruck, S., \& Lucas, K. (2003). Pareto Optimization of a Combined Cycle Power System as a Decision Support Tool for Trading off Investment vs. Operating Costs. International Journal of Thermal Sciences, 42 (6), 553-560.

10. Deb, K. (2001). Multi-objective Optimization Using Evolutionary Algorithms. Chichester: Wiley.

11. Deb, K., \& Goel, T. (2001). Controlled Elitist Non-Dominated Sorting Genetic Algorithms for Better Convergence. EMO 2001: Evolutionary Multi-Criterion Optimization, 67-81. 
12. Srinivas, N., \& Deb, K. (1994). MultiObjective Optimization Using NonDominated Sorting in Genetic Algorithms. Journal of Evolutionary Computing, 2 (3), 221-248.

13. Toffolo, A., \& Lazzaretto, A. (2004). Energy, Economy and Environment as Objectives in Multi-Criteria Optimization of Thermal System Design. Energy, 29, 1139-1157.

14. NordPool. (n.d.). Simple, Efficient \& Secure. Available at https://www.nordpoolgroup. com/

15. Mallawaarachchi, V. (2017). Introduction to Genetic Algorithms - Including Example Code. Available at https:// towardsdatascience.com/introduction-togenetic-algorithms-including-examplecode-e396e98d8bf3
16. Kaggle. (2019). Genetic Algorithm with $D E A P$. Available at https://www.kaggle. $\mathrm{com} / \mathrm{marlesson} /$ genetic-algorithm-withdeap

17. Cavaliere, A. (2007). The Liberalization of Natural Gas Markets: Regulatory Reform and Competition Failures in Italy. Available at https://www.oxfordenergy.org/ publications 